ARTICLE

\title{
Super hygroscopic nanofibrous membrane-based moisture pump for solar-driven indoor dehumidification
}

\author{
Yufei Zhang ${ }^{1}$, Lei $\mathrm{Wu}^{2}$, Xianfeng Wang ${ }^{1,3 凶}$, Jianyong $\mathrm{Yu}^{3} \&$ Bin Ding ${ }^{1,3 凶}$
}

Desiccants play vital roles in dehumidification and atmospheric water harvesting; however, current desiccants have mediocre hygroscopicity, limited recyclability, and high energy consumption. Herein, we report a wood-inspired moisture pump based on electrospun nanofibrous membrane for solar-driven continuous indoor dehumidification. The developed moisture pump with multilayer wood-like cellular networks and interconnected open channels is composed of a desiccant layer and a photothermal layer. The desiccant layer exhibits an unprecedented moisture absorption capacity of $3.01 \mathrm{~g} \mathrm{~g}^{-1}$ at $90 \%$ relative humidity (RH), fast moisture absorption and transport rates, enabling atmospheric water harvesting. The photothermal layer shows a high solar absorption of $93 \%$, efficient solar thermal conversion, and good moisture permeability, thus promoting water evaporation. The moisture pump efficiently reduces the indoor relative humidity to a comfort level (40-60\% RH) under onesun illumination. This work opens the way to develop new-generation, high-performance nanofibrous membrane-based desiccants for energy-efficient humidity control and atmospheric water harvesting.

\footnotetext{
${ }^{1}$ State Key Laboratory for Modification of Chemical Fibers and Polymer Materials, College of Textiles, Donghua University, Shanghai 201620, China. ${ }^{2}$ College of Textile Materials and Engineering, Wuyi University, Jiangmen 529020, China. ${ }^{3}$ Innovation Center for Textile Science and Technology, Donghua University,

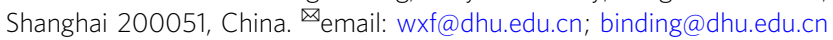


A mbient humidity regulation has gained increasing concern in recent years due to its vital role in dehumidification ${ }^{1,2}$. One of the most critical challenges in indoor environments is regulating the humidity because high humidity can make people uncomfortable, cause furniture and clothes to become moldy, and accelerate damage to electronic equipment ${ }^{3,4}$. Thus, dehumidification is necessary in many highhumidity environments. The appropriate indoor relative humidity $(\mathrm{RH})$ level for a healthy and comfortable environment in inhabited buildings ranges from 40 to $60 \% 5$. In addition, atmospheric humidity is widely considered as a redundant source of water, and energy is required to sustain comfortable humidity levels within living spaces ${ }^{6}$. Atmospheric water harvesting occurs during dehumidification, and the production of fresh water via moisture collection from humid air also shows great potential for sustainable water delivery ${ }^{7-9}$.

Conventional air-conditioning systems dehumidify air by cooling it below the dew point temperature to remove moisture via condensation, and then reheating it to the required temperature, which requires high energy consumption ${ }^{10}$. Various novel ideas for energy-saving technologies in buildings have recently emerged ${ }^{11-13}$. Therefore, independent humidity control systems need to be developed to achieve the desired balance between energy consumption and indoor comfort. As we all know, moisture can be autonomously transported from highhumidity to low-humidity environments through membranes. According to the thermo-osmosis theory, moisture can also be transported from a low-humidity to a high-humidity environment under the driving force of thermal gradients in a membrane ${ }^{14}$. This pathway or mode of moisture transport is referred to a moisture pump and is analogous to a heat pump. Extensive studies have recently been performed regarding the highefficiency use of solar energy for surface-localized heating and steam generation ${ }^{15-17}$. Therefore, solar-driven moisture pump dehumidification technology is particularly attractive because of the abundance of solar energy, which results in significant energysaving potential and ecological and economic benefits.

To regulate indoor humidity levels to achieve comfortable environments, an ideal desiccant material for a moisture pump should rapidly absorb moisture when the humidity level exceeds $60 \% \mathrm{RH}$. In addition, the desiccant must be highly hygroscopic, recyclable, have a fast moisture absorption rate, and be capable of driving the phase transition from gaseous water to liquid water. In this respect, metal-organic frameworks (MOFs) are attractive and promising due to their high-specific surface area and porosity, adjustable pore size, as well as a large number of hydrophilic active sites, thereby facilitating the rational design of the desired water sorption properties ${ }^{18-22}$. Yan et al. reported that the water vapor absorption capacity of MIL-101(Cr) reached $1.22 \mathrm{~g} \mathrm{~g}^{-1}$ at $25^{\circ} \mathrm{C}$ and $90 \% \mathrm{RH}$, and its superior water vapor absorption made it a promising water vapor adsorbent ${ }^{23}$. Cao et al. proposed a silica gel-MIL-101(Cr)-based moisturepermeable panel prepared using a partial immersion method, which could reduce the indoor RH to a medium level ${ }^{24}$. However, the MIL-101(Cr) particles easily agglomerated, which reduced its water vapor transmission (WVT) and dehumidification capabilities. In addition, conventional membrane separation technique used for dehumidification is based on solution diffusion mechanism, which is energy-saving and environmentally friendly, but the moisture permeability is low ${ }^{25}$. To tackle the above issues, it is highly desirable to develop self-supporting and flexible MOF nanofibrous membrane (NFM)-based desiccants with highly porous structures and a large number of active sites for moisture absorption and water harvesting.

Electrospinning is a low-cost and scalable technology for preparing MOF NFMs because the nanofibrous structure of the resulting materials facilitates fast moisture absorption-desorption $^{26-28}$. To further improve the moisture absorption sensitivity and capacity of NFM, a moisture-sensitive material such as $\mathrm{LiCl}$ can be loaded into/onto the nanofibers ${ }^{28,29}$. However, $\mathrm{LiCl}$ is prone to loss via deliquescence, and excessively high $\mathrm{LiCl}$ contents in composite desiccants will lead to problems such as salt precipitation and agglomeration, resulting in poor strength and recyclability ${ }^{30-32}$. To solve these issues, it is feasible to adopt dilute $\mathrm{LiCl}$ solutions to impregnate MOF NFMs. The hierarchical pore structures of both the MOF and nanofibers provide good support for $\mathrm{LiCl}$ to reduce the loss of $\mathrm{LiCl}$, maintaining the moisture absorption stability of the NFM-based desiccant. Thus, the synergistic effect of the MOF and $\mathrm{LiCl}$ as well as the nanofibrous structure make it possible to design NFMbased desiccants with superior hygroscopicity, fast moisture absorption-desorption rates, and superior recyclability.

In trees, the microchannels of natural woods served as pathways to pump and transport water from the ground via transpiration ${ }^{33,34}$, which inspired the fabrication of biomimetic wood-like NFMs. Herein, we present a wood-inspired NFMbased moisture pump (biomimetic bilayer NFM) using a facile and scalable two-step electrospinning and impregnation method for solar-driven indoor dehumidification. To the best of our knowledge, there have been no previous reports on MOF NFMbased moisture pumps for continuous indoor dehumidification under sunlight illumination. The developed moisture pump with multilayer wood-like cellular networks and interconnected open channels is composed of a desiccant layer and a photothermal layer. The desiccant layer with high-specific surface area and porosity exhibits an unprecedented moisture absorption capacity of $3.01 \mathrm{~g} \mathrm{~g}^{-1}$ at $25^{\circ} \mathrm{C}$ and $90 \% \mathrm{RH}$, fast moisture absorption and transport rates, as well as superior long-term stability, enabling atmospheric water harvesting. The photothermal layer displays a high solar absorption of $93 \%$, efficient solar thermal conversion, and good moisture permeability, thus promoting water evaporation. This work reveals that a biomimetic NFM-based desiccant can potentially be applied for solar-driven moisture pump dehumidification and efficient atmospheric water harvesting.

\section{Results}

Wood-inspired design for the NFM-based moisture pump. Natural wood from a tree trunk displays special structures with horizontal hierarchical cellular networks and vertical interconnected channels that pump and transport water from the ground upstream via transpiration (Fig. 1a-c). Inspired by this special structures and unique functional characteristics, a biomimetic wood-like NFM was developed (Fig. 1d) for moisture absorption and water vapor evaporation. The NFM surface presented a neatly arranged wood-like cellular network structure. High-magnification scanning electron microscopy (SEM) image showed a single cell with a pore size of $\sim 1 \mathrm{~mm}$ (inset of Fig. 1d). As demonstrated in Fig. 1e, the fabrication began with the PAN/ MIL-101(Cr) (PAN/MIL) NFM with a multilayer wood-like cellular network structure obtained directly by electrospinning. Then, the PAN/MIL NFM was impregnated by the $\mathrm{LiCl}$ solution to obtain PAN/MIL-101(Cr)@LiCl (PAN/MIL@LiCl) NFM. Due to the highly porous structure and fluffy multilayered architecture of PAN/MIL NFM, LiCl effectively penetrated the surface layer and entered the inner layer of the NFM and the porous nanofibers. Subsequently, the polyacrylonitrile/carbon black (PAN/CB) nanofibers were electrospun on the PAN/MIL@LiCl nanofibrous substrate to construct the biomimetic bilayer PAN/MIL@LiClPAN/CB (PML-PC) NFM (the middle inset of Fig. 1e). Schematic structures of the moisture-permeable bilayer NFM and proposed 


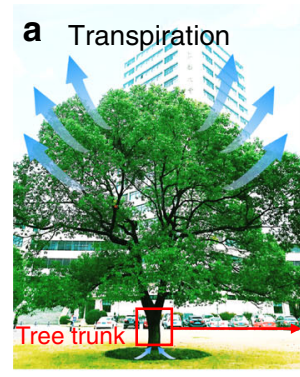

e

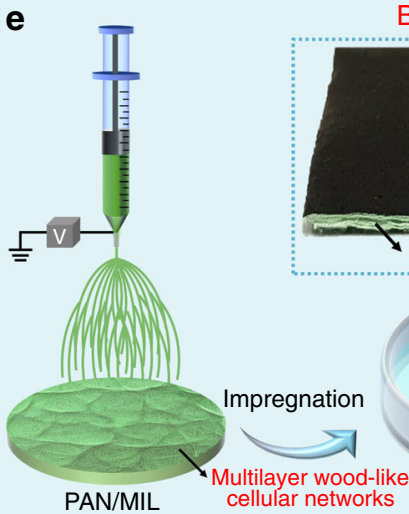

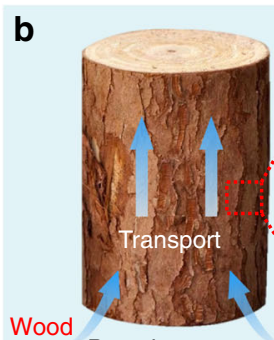

Pumping water
Bilayer PML-PC $\mathrm{PAN} / \mathrm{CB}$

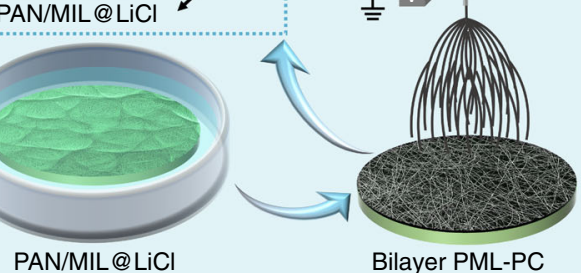

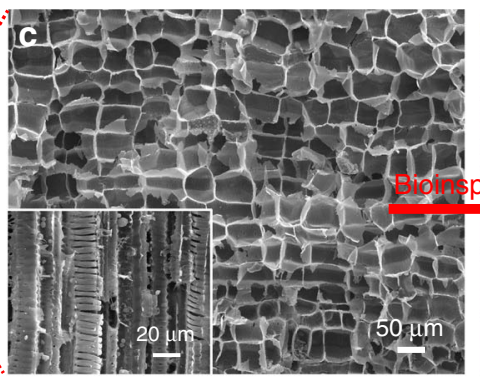

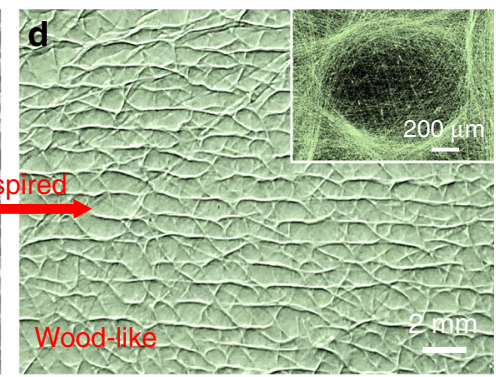

f

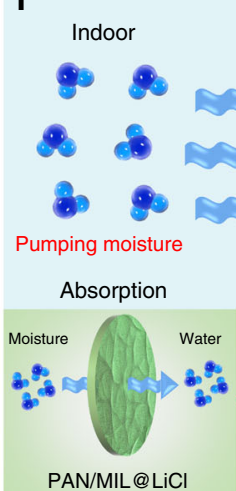

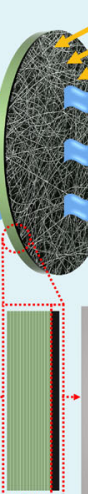

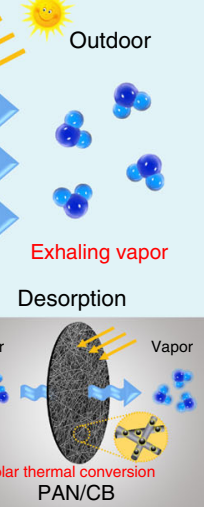

Fig. 1 Wood-inspired design for the NFM-based moisture pump. a-c Natural wood obtained from a tree trunk contains special structures with horizontal

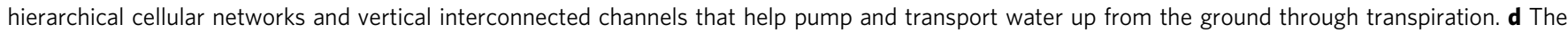
macro morphology of biomimetic PAN/MIL NFM with a wood-like cellular network structure. The inset shows a high-magnification SEM image of a single cell in the PAN/MIL NFM. e Schematic illustration of the fabrication of biomimetic bilayer PML-PC NFM. The PAN/CB nanofibers were directly electrospun on the multilayer wood-like cellular network substrate of the PAN/MIL@LiCl nanofibers. The middle inset shows the developed bilayer NFM. f Schematic structures of the moisture-permeable bilayer NFM and proposed moisture transport path under sunlight illumination. The absorbed water molecules are transported outdoors by passing through the desiccant layer and photothermal layer.

moisture transport path are shown in Fig. 1f. The biomimetic bilayer PML-PC NFM with wood-like cellular networks and interconnected open channels can perform moisture pumping and vapor exhaling. Notably, the desiccant layer (PAN/MIL@LiCl NFM) was responsible for absorbing moisture from indoor air, and absorbed water molecules were desorbed by the heat generated by solar thermal conversion of the photothermal layer (PAN/CB NFM) under sunlight illumination. The absorbed water molecules were transported outdoors by passing through the desiccant layer and photothermal layer. In this way, the proposed biomimetic bilayer NFM design can achieve high-efficiency and continuous indoor dehumidification under a solar irradiation, to serve as an NFM-based moisture pump.

Morphology and structure characterizations of the desiccant layer. The micromorphologies of the biomimetic wood-like PAN/ MIL NFM are shown in Fig. 2a-d. Of particular interest is that electrospinning technology enabled the assembly of PAN/MIL nanofibers into a highly ordered cellular network architecture consisting of unit cells, interconnected nanofibrous cell walls, and aligned and uniform nanofibers, mimicking the wood structure in both the horizontal and vertical directions. In addition, the merged nanofiber clusters were locally oriented along the edges of the cellular networks, which facilitated water diffusion and water evaporation. The as-prepared light green PAN/MIL NFM showed excellent flexibility and a multilayered architecture (inset of Fig. 2c). Typically, we were excited to find that MIL-101(Cr) nanoparticles were evenly distributed throughout nanofibers, showing that the developed nanofibers had a hierarchical roughness and nanoporous structure (Fig. 2d). The porous structure was conducive to moisture absorption and vapor diffusion $^{35}$. The formation of a cellular network structure may be attributed to the competitive action of surface tension and electrostatic repulsion of the wet electrospun nanofibers ${ }^{36,37}$. We propose a simplified model to elucidate the three-dimensional (3D) self-assembly mechanism of the multilayer wood-like cellular network structure of PAN/MIL NFM (Fig. 2e). As the wet nanofibers were deposited and came into contact with the partially overlapped nanofiber clusters, surface tension may have driven the portion near the contact point to merge into nanofiber clusters, resulting in the charge accumulation on the surface of the nanofibers and the increase of electrostatic repulsion between the nanofibers. With the increase of electrostatic repulsion, the nanofibers far from the contact point may have bent outward. Finally, the nanofiber clusters were reversely bent to form a threebranched structure. Based on this, the deposited nanofibers were stacked layer-by-layer and formed 3D multilayer cellular networks composed of many three-branched clusters. Simultaneously, the addition of MIL-101(Cr) nanoparticles increased the conductivity of the electrospinning solution. The charged droplets acted as suspended clusters, which underwent rapid self-assembly via dissipation to minimize their energy ${ }^{38}$. Rapid stretching deformation due to the differential microelectric fields and additional solvent evaporation led to the formation of nanofiber assemblies with cellular networks.

Figure $2 \mathrm{f}$ presents the transmission electron microscopy (TEM) image of the PAN/MIL nanofiber, revealing that interconnected MIL-101(Cr) crystals were evenly arranged along the surface and inside the nanofibers. The dimension of single MIL-101(Cr) crystals was around $800 \mathrm{~nm}$ (Fig. 2g), indicating that the uniform nano-sized MIL-101(Cr) crystals and nanofibers had compatible sizes, which is helpful for electrospinning. PAN/MIL NFM was coated with $\mathrm{LiCl}$ via impregnation to improve its moisture absorption performance. The diameters of the PAN/MIL@LiCl 

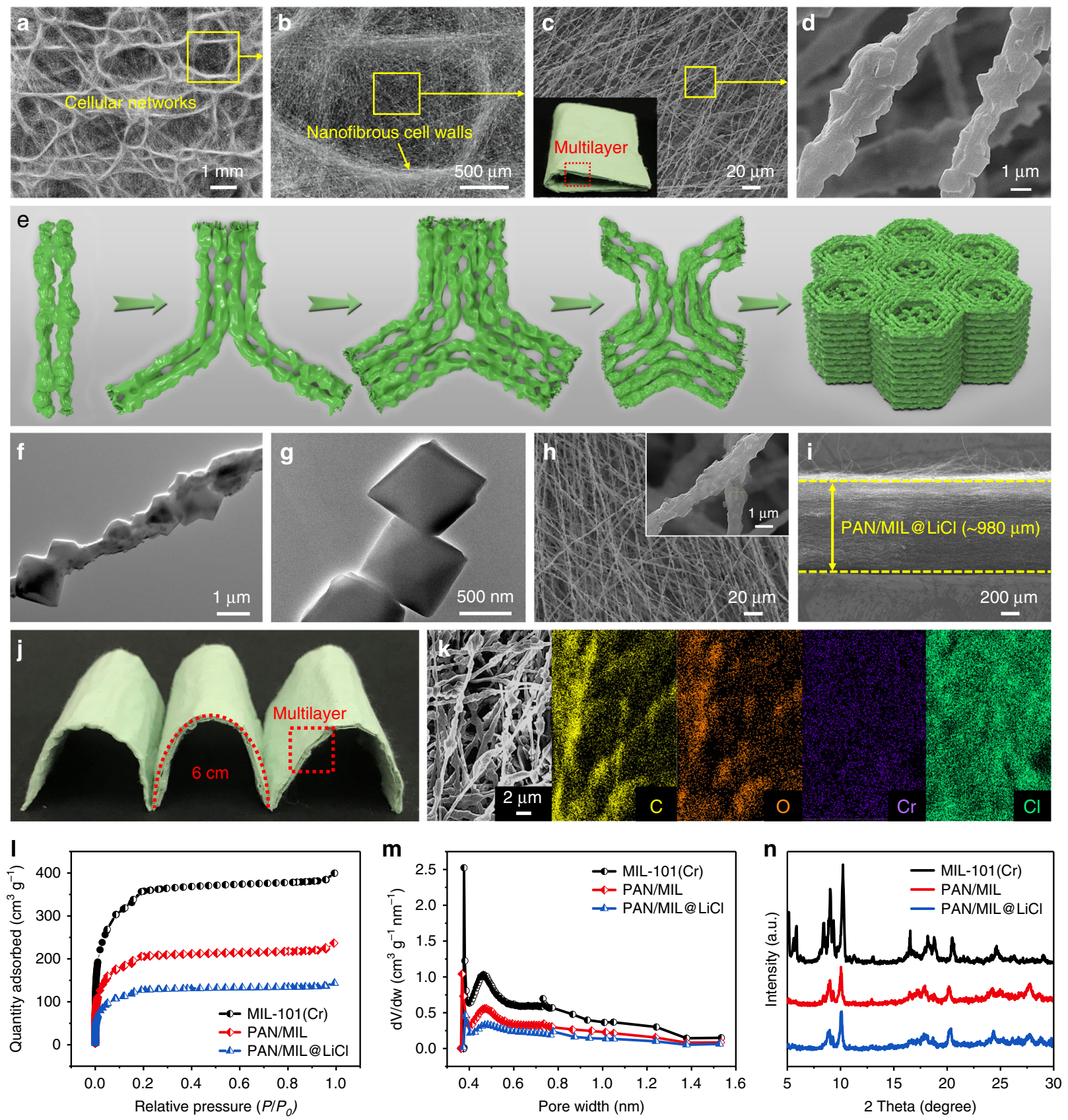

Fig. 2 Morphology and structure characterizations of the desiccant layer. a-d SEM images at increasing magnifications demonstrating the biomimetic wood-like cellular network structure of PAN/MIL NFM. The inset in (c) is the as-prepared flexible PAN/MIL NFM photograph with a multilayered architecture. e Schematic showing the 3D self-assembly mechanism of PAN/MIL NFM with a multilayer wood-like cellular network structure. TEM images of (f) PAN/MIL nanofiber and ( $\mathbf{g}$ ) pure MIL-101(Cr) crystals. h, i Top-down and cross-section SEM images of PAN/MIL@LiCl NFM. The inset in (h) is a high-magnification SEM image. j Photograph demonstrating the flexibility of PAN/MIL@LiCI NFM and its multilayered architecture. $\mathbf{k}$ FE-SEM image and corresponding elemental maps of PAN/MIL@LiCI NFM. I N $\mathrm{N}_{2}$ adsorption-desorption isotherms, $\mathbf{m}$ pore size distribution curves, and $\mathbf{n}$ XRD patterns of MIL101(Cr) nanoparticles, PAN/MIL, and PAN/MIL@LiCI NFMs, respectively.

nanofibers were uniform (Fig. 2h). High-magnification SEM image clearly exhibited that the nanofibers retained their hierarchical roughness and nanotextures (inset of Fig. 2h), showing that the $\mathrm{LiCl}$ coating did not substantially destroy the original morphology. The cross-sectional image of PAN/ MIL@LiCl NFM in Fig. 2i shows that the fluffy multilayer NFM had a thickness of $\sim 980 \mu \mathrm{m}$, and it also retained flexible nature and multilayered architecture (Fig. 2j). Interestingly, the multilayer NFM could be stripped layer-by-layer (Supplementary Fig. 1). Furthermore, the field emission scanning electron microscopy (FE-SEM) image and corresponding elemental maps of PAN/MIL@LiCl NFM were obtained (Fig. 2k). Cr and O derived from MIL-101(Cr) were uniformly distributed along the PAN nanofibers along with C, further revealing that the MIL-101 (Cr) crystals were homogenously distributed on the nanofibers. In addition, the distribution of $\mathrm{Cl}$ confirmed that $\mathrm{LiCl}$ was completely and uniformly distributed throughout the membrane.

Considering that the porous structure feature is a vital element in desiccant materials, the samples were systematically investigated via $\mathrm{N}_{2}$ adsorption-desorption measurements. All isotherms 
a

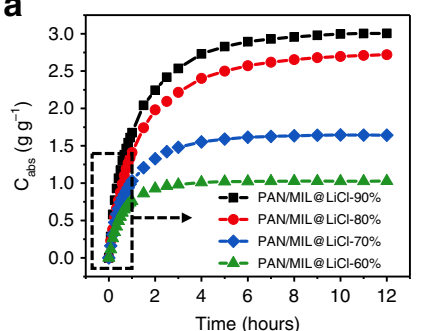

b

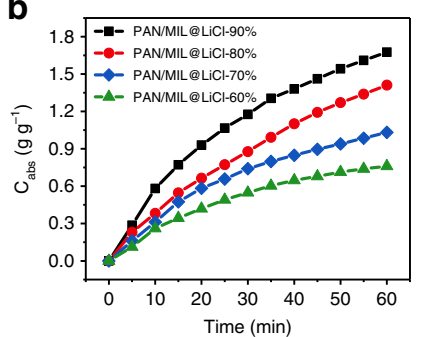

C

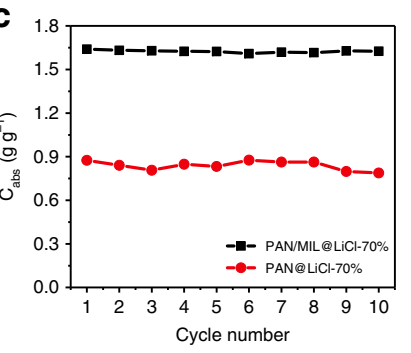

d

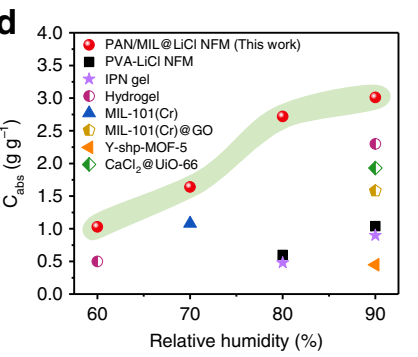

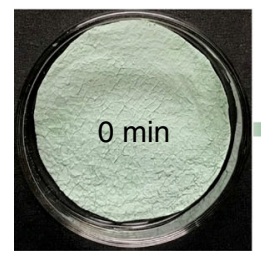

$\mathbf{f}$
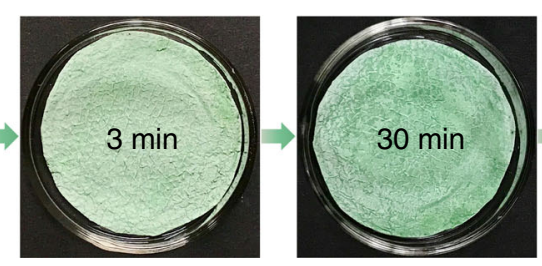

g
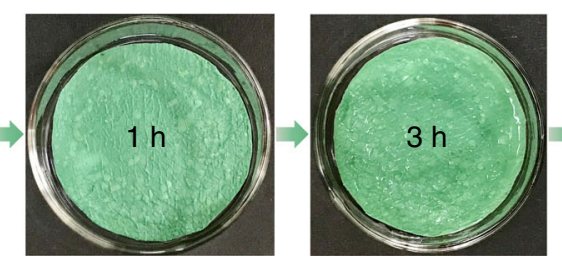

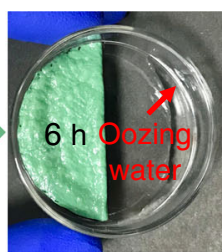

h
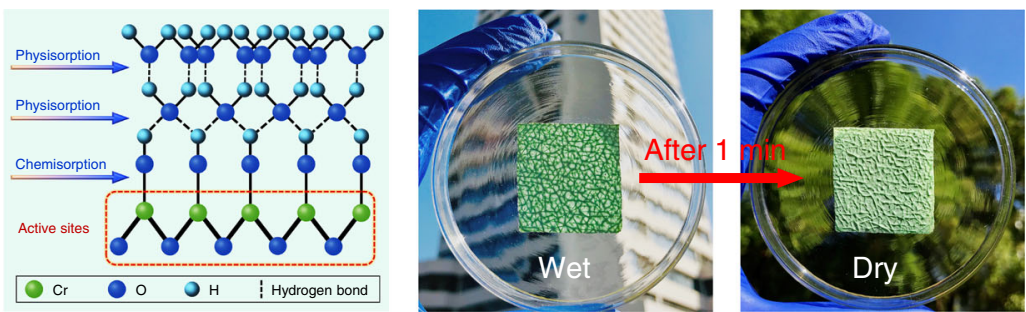

Fig. 3 Moisture absorption and water oozing behaviors of the desiccant layer. a, b Moisture absorption kinetics of PAN/MIL@LiCl NFM at $25^{\circ} \mathrm{C}$ and various humidities. c Cycling stability of moisture absorption-desorption of PAN/MIL@LiCl and PAN@LiCl NFMs at $25^{\circ} \mathrm{C}$ and $70 \%$ RH (desorption at $100^{\circ} \mathrm{C}$ ). d A comparative chart of the moisture absorption capacity for some reported representative desiccant materials: PVA-LiCI NFM ${ }^{27}$, IPN gel ${ }^{41}$, and hydrogel ${ }^{42}$. MIL-101(Cr) ${ }^{24}$, MIL-101(Cr)@GO23, Y-shp-MOF-53, and $\mathrm{CaCl}_{2} @ U$ UiO-66 63 .e Optical photographs revealing surface moisture absorption, water oozing, and color change of PAN/MIL@LiCI NFM at $25^{\circ} \mathrm{C}$ and $90 \%$ RH. $\mathbf{f}$ Schematic displaying the moisture absorption and water oozing behaviors of PAN/MIL@LiCI NFM. $\mathbf{g}$ Schematic showing the water absorption mechanism of MIL-101(Cr) in the PAN/MIL@LiCl NFM. h Optical photographs of the stripped monolayer PAN/MIL@LiCl NFM after moisture absorption and drying.

exhibited typical type I isotherms without obvious hysteresis loops (Fig. 2l). The rapid adsorption equilibrium may be ascribed to micropore filling, indicating that a large amount of micropores existed in MIL-101(Cr) nanoparticles and NFMs. According to Horvath-Kawazoe (HK) model and density functional theory (DFT) method, the corresponding pore size distribution (PSD) curves showed that the micropore sizes were centered around $0.40-0.75 \mathrm{~nm}$ (Fig. $2 \mathrm{~m}$ ), which was larger than the kinetic diameter $(0.27-0.32 \mathrm{~nm})$ of a water molecule ${ }^{39}$, thus promoting moisture absorption and water vapor diffusion. The Brunauer-Emmett-Teller (BET)-specific surface area and pore structure parameters are listed in Supplementary Table 1. PAN/MIL NFM provided a large number of sites for LiCl loading due to its high-specific surface area $\left(724 \mathrm{~m}^{2} \mathrm{~g}^{-1}\right)$ and porosity. Nevertheless, the BET-specific surface area $\left(S_{\mathrm{BET}}\right)$ decreased to $398 \mathrm{~m}^{2} \mathrm{~g}^{-1}$ after $\mathrm{LiCl}$ coating, implying that $\mathrm{LiCl}$ coating blocked some of the pores. As presented in Fig. 2n, characteristic peaks of MIL-101(Cr) were clearly visible in the X-ray diffraction (XRD) pattern of the synthesized MIL-101(Cr) crystals. The diffraction patterns of the PAN/MIL and PAN/MIL@LiCl NFMs closely matched that of MIL-101(Cr) crystals, revealing the existence of well-defined MOF in the NFMs and the amorphous structure of $\mathrm{LiCl}$ in PAN/MIL@LiCl NFM.

Moisture absorption and water oozing behaviors of the desiccant layer. The moisture absorption behaviors of PAN/MIL@LiCl NFM were gravimetrically evaluated at $25^{\circ} \mathrm{C}$ and various humidities. As observed in Fig. 3a, the moisture absorption capacities of dried PAN/MIL@LiCl NFM at 60\%,70\%,80\%, and
$90 \% \mathrm{RH}$ reached $1.03,1.64,2.72$, and $3.01 \mathrm{~g} \mathrm{~g}^{-1}$, respectively. It should be noted that the PAN/MIL@LiCl NFM quickly absorbed moisture from humid air within an hour (Fig. 3b). The absorbed water content and the time to reach saturation significantly increased with increasing ambient humidity because more water molecules were able to combine with active sites on the NFM. In terms of materials and structures, the synergistic effect of MIL$101(\mathrm{Cr})$ and $\mathrm{LiCl}$ in the desiccant layer imparted the material with super hygroscopicity, and the porous nanofibrous structure significantly increased the moisture absorption and transport rates. First, MIL-101 (Cr) had a large-specific surface area, high porosity, and rich hydrophilic active sites ( $\mathrm{Cr}-\mathrm{O}$ clusters), which were conducive to the absorption of water molecules. In addition, the nanofibrous structure facilitated fast moisture absorption, and $\mathrm{LiCl}$ reduced the water vapor pressure on the NFM surface, resulting in a greater driving force for water diffusion, thereby greatly improving the moisture absorption capacity and humidity sensitivity of PAN/MIL@LiCl NFM ${ }^{40}$.

To ensure low energy consumption in practical applications, continuous dehumidification is required for desiccants used in energy exchange systems, such as moisture pumps and dehumidifiers ${ }^{41}$. Thus, the moisture absorption-desorption cycling stability for the NFM must be considered. As shown in Fig. 3c, PAN@LiCl NFM was prepared (Supplementary methods) to provide a comparison to PAN/MIL@LiCl NFM. The moisture absorption capacity of PAN/MIL@LiCl NFM at $25^{\circ} \mathrm{C}$ and $70 \%$ RH was much higher than that of PAN@LiCl NFM, indicating that the introduction of the MOF further improved the hygroscopicity and recyclability of the NFM. Evidently, the 
moisture absorption capacity of PAN/MIL NFM remained at $89.8 \%\left(0.79 \mathrm{~g} \mathrm{~g}^{-1}\right)$ of its initial capacity $\left(0.88 \mathrm{~g} \mathrm{~g}^{-1}\right)$ after ten cycles, whereas PAN/MIL@LiCl NFM retained 99.4\% (1.63 $\left.\mathrm{g} \mathrm{g}^{-1}\right)$ of its initial capacity $\left(1.64 \mathrm{gg}^{-1}\right)$. Significantly, the pore structure of MIL-101(Cr) and porous nanofibrous structure of PAN/MIL NFM provided good support for $\mathrm{LiCl}$ to form the PAN/MIL@LiCl NFM. With the assistance of the pores and channels of PAN/MIL@LiCl NFM, LiCl loss was avoided as much as possible, which enhanced the long-term stability of the NFM. To further evaluate the advantages of PAN/MIL@LiCl NFM for moisture absorption, the absorption capacity was quantitatively compared with previously reported desiccant materials (Fig. 3d) $3,23,24,28,41-43$. Obviously, PAN/MIL@LiCl NFM in this work exhibited superior hygroscopicity at $25^{\circ} \mathrm{C}$ and various humidities compared with other desiccants. As a result, PAN/MIL@LiCl NFM can fully meet the needs of practical applications and can be easily operated at ambient temperature, surpassing the performance of other granular solid desiccant materials.

To observe water harvesting after moisture absorption, we placed PAN/MIL@LiCl NFM at $25^{\circ} \mathrm{C}$ and $90 \%$ RH for a certain time. Figure $3 \mathrm{e}$ shows that the NFM quickly absorbed moisture in a short time (moisture absorption sensitivity), and the color of the NFM gradually deepened after moisture absorption. The NFM surface began to ooze water after $3 \mathrm{~h}$, and the amount of liquid water increased with the moisture absorption time. Liquid water appeared in the watch glass after $6 \mathrm{~h}$. Figure $3 \mathrm{f}$ displays the moisture absorption and water oozing behaviors of PAN/ MIL@LiCl NFM. Water molecules were absorbed and liquefied on the surface of the NFM, mainly due to the presence of hygroscopic $\mathrm{LiCl}$ and MOF. Water then diffused into the porous networks of the NFM, enabling water to be captured from the moist air. The multilayer cellular networks of hydrophilic PAN/ MIL@LiCl NFM facilitated water storage. As a result, liquid water was directly harvested from the humid air by absorbing moisture (gas) and oozing water using PAN/MIL@LiCl NFM without energy consumption (latent heat of evaporation and condensation $)^{41}$. This unique property demonstrates the possibility of applying the PAN/MIL@LiCl NFM as an energy-efficient material that converts gaseous water into liquid water.

Figure $3 \mathrm{~g}$ further elaborates on the water absorption mechanism of MIL-101(Cr) in PAN/MIL@LiCl NFM. First, water molecules were chemically absorbed on the active sites of the NFM, resulting in dissociation to form continuous hydroxyl groups. Subsequently, two adjacent hydroxyl groups absorbed water molecules via double hydrogen bonds to form the first physical absorption layer. At high $\mathrm{RH}$, water molecules completely covered the NFM surface to form the first liquid water layer. Then, the reabsorbed water molecules formed a continuous network of liquid water layers by single hydrogen bonds ${ }^{44-46}$. The moisture absorption process was accompanied by irreversible (hysteretic) capillary condensation ${ }^{7}$. Eventually, the capacity of absorbed water molecules gradually reached saturation, and water oozing occurs. Although water oozing from the NFM still needs further research to improve efficiency, the use of NFM for moisture absorption and water harvesting is likely to become a promising system in the future. The phase transition of water molecules from the gas phase to the liquid phase using a dried membrane will open up a variety of possibilities for developing flexible desiccants for energy exchange systems with low energy consumption. In addition, it was particularly interesting that the stripped monolayer PAN/MIL@LiCl NFM was dried after 1 min under natural sunlight, demonstrating an obvious hierarchical cellular network structure (Fig. 3h). This indicated that the wood-like monolayer NFM exhibited an ultrafast water diffusion and evaporation rate under sunlight illumination.
Characterizations and properties of the photothermal layer. To achieve water vapor evaporation of the desiccant layer under sunlight, PAN/CB NFM was prepared as a photothermal layer based on PAN/MIL@LiCl NFM. The SEM images shown in Fig. 4a, b demonstrate that PAN/CB NFM was comprised of highly open $3 \mathrm{D}$ nanofiber networks $(\sim 480 \mathrm{~nm})$ that provided channels for water evaporation. Figure $4 \mathrm{c}$ presents a TEM image of $\mathrm{PAN} / \mathrm{CB}$ nanofibers that shows that $\mathrm{CB}$ nanoparticles were uniformly embedded in the nanofiber to form a rough surface. The rough surface of the PAN/CB nanofibers and the introduction of $\mathrm{CB}$ nanoparticles greatly enhanced the scattering of incident light within the photothermal layer, which improved the efficient absorption of broadband solar radiation. Thus, the generated heat was effectively confined within the photothermal layer with minimal loss to the air, which enhanced water evaporation. Photographs of folding and twisting PAN/CB NFM demonstrate its excellent flexibility and bending recovery (Fig. 4d). The Raman spectra also showed that CB nanoparticles were successfully incorporated into the PAN nanofibers (Fig. 4e). For the PAN NFM, there was no apparent characteristic peak, whereas two broad characteristic peaks near 1350 and $1600 \mathrm{~cm}^{-1}$ were observed in the Raman spectrum of PAN/CB NFM, which corresponded to the $\mathrm{D}$ and $\mathrm{G}$ bands of carbon, respectively ${ }^{47,48}$. PAN/CB NFM had a high solar absorption of $93 \%$ within a broad wavelength from 250 to $2500 \mathrm{~nm}$ in a standard solar spectrum (AM1.5 G), which was much higher than that of PAN NFM (Fig. 4f). To investigate the moisture permeability, WVT tests were carried out. The five curves of PAN, PAN/MIL, PAN/ MIL@LiCl, PAN/CB, and bilayer PML-PC NFMs were nearly identical (Supplementary Fig. 2), indicating that the addition of MIL-101(Cr) or CB and the LiCl coating did not affect the WVT ability. This was ascribed to the nano-scale particle size and small aggregation domains of particles, which did not significantly change the pore and channel structures. In addition, numerous macropores were formed between the electrospun nanofibers. Therefore, both the desiccant layer and photothermal layer had good moisture permeability.

With a high broadband solar absorption, fast moisture transport, and good moisture permeability, the bilayer PML-PC NFM achieved efficient solar thermal conversion and enhanced water vapor evaporation under one-sun illumination. Figure $4 \mathrm{~g}$ demonstrates the moisture transport and vapor-out processes of the biomimetic bilayer PML-PC NFM under a solar irradiation. To illustrate the importance of the photothermal layer, the surface temperature distribution of the PAN/MIL@LiCl NFM and bilayer PML-PC NFM under one-sun illumination was recorded by an infrared (IR) thermal camera (Fig. 4h). The initial surface temperatures of PAN/MIL@LiCl NFM $\left(20.4^{\circ} \mathrm{C}\right)$ and bilayer PML-PC NFM $\left(20.5^{\circ} \mathrm{C}\right)$ were nearly identical before illumination. However, the surface temperature of the bilayer PML-PC NFM rapidly increased within a few minutes and reached $74.3^{\circ} \mathrm{C}$ after $60 \mathrm{~min}$ (Fig. 4i). The excellent heat confinement of the bilayer PML-PC NFM under low-intensity illumination shows that the material has efficient solar thermal conversion, which can promote solar-driven water evaporation. To investigate the evaporation performance, the cumulative mass losses of PAN/ MIL@LiCl NFM and bilayer PML-PC NFM were measured under simulated sunlight irradiation of $1 \mathrm{~kW} \mathrm{~m}^{-2}$. The mass loss was nearly linear within the first $10 \mathrm{~min}$, after which the evaporation rate slowed and gradually stabilized (Fig. 4j, k). Bilayer PML-PC NFM had a fast evaporation rate and achieved quick moisture desorption and dried out within 20 min under a solar irradiation. After $20 \mathrm{~min}$ of one-sun illumination, the evaporation rate of bilayer PML-PC NFM was $1.47 \mathrm{~kg} \mathrm{~m}^{-2} \mathrm{~h}^{-1}$, which was much higher than that of the NFM without a photothermal layer $\left(0.87 \mathrm{~kg} \mathrm{~m}^{-2} \mathrm{~h}^{-1}\right)$. Therefore, these facts confirm that the 
a

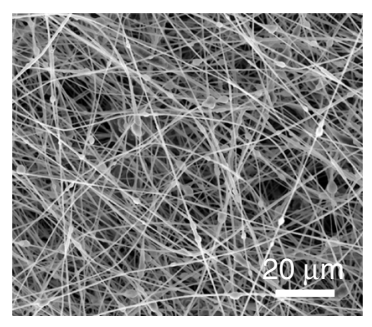

b

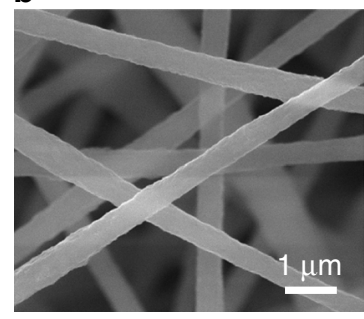

C

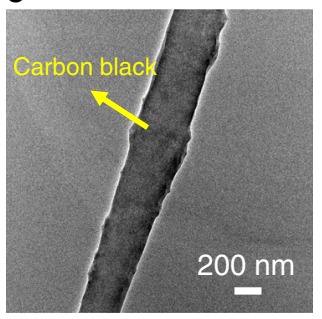

d

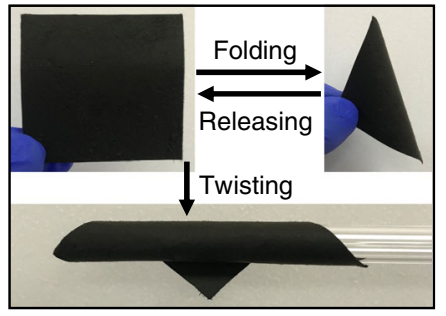

e
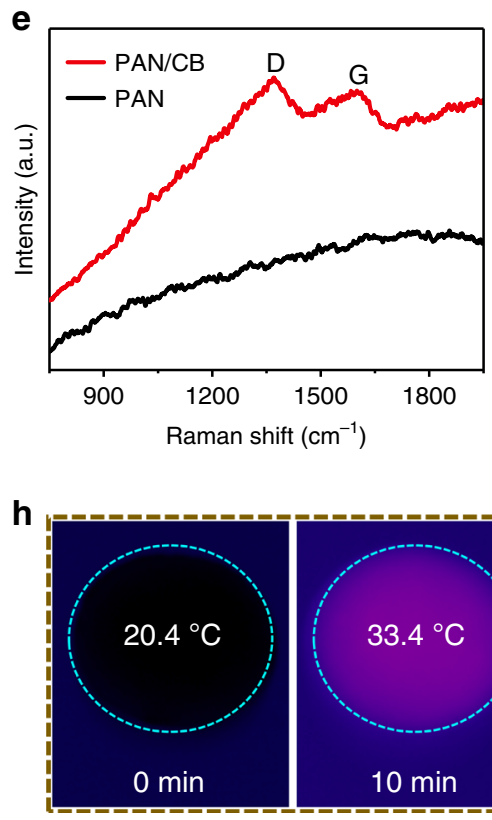

f

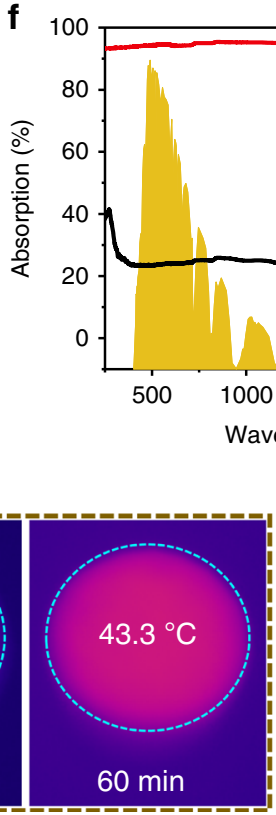

$60 \mathrm{~min}$

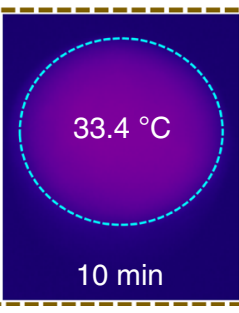

PAN/MIL@LiCl i

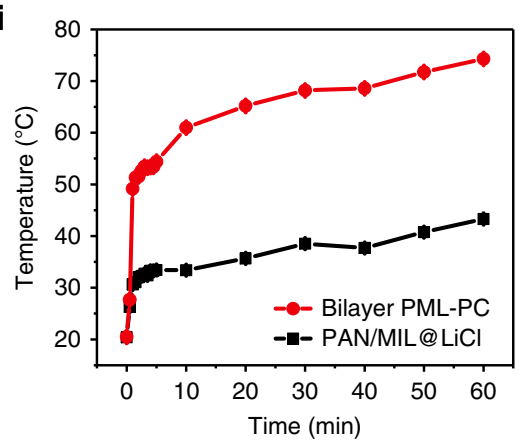

j

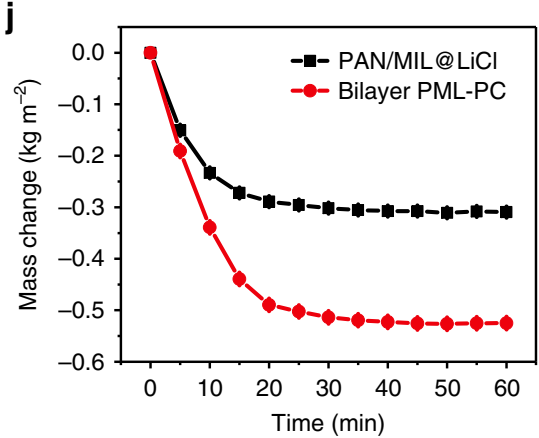

g

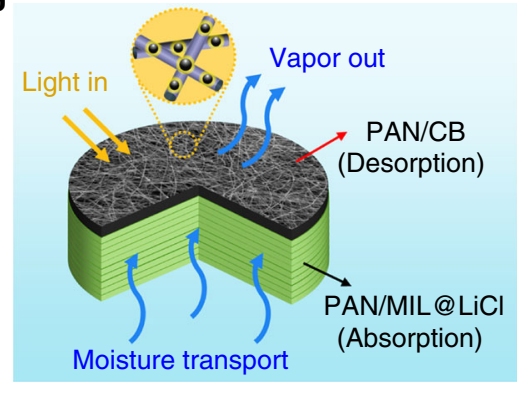

Wavelength $(\mathrm{nm})$

$90^{\circ} \mathrm{C}$
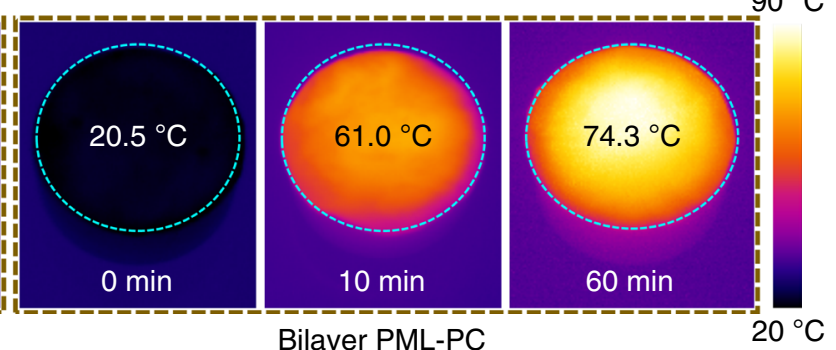

Bilayer PML-PC

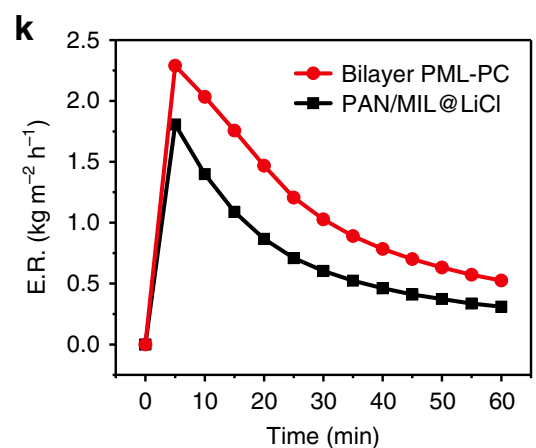

Fig. 4 Characterizations and properties of the photothermal layer. a, b SEM images of PAN/CB NFM. $\mathbf{c}$ TEM image of PAN/CB nanofiber. $\mathbf{d}$ Photographs of folding and twisting tests of PAN/CB NFM. e Raman spectra of PAN/CB and PAN NFMs. $\mathbf{f}$ Light absorption of PAN/CB and PAN NFMs. Solar spectral irradiance (yellow shadow) weighted by standard AM1.5 G solar spectrum. $\mathbf{g}$ Schematic of the moisture transport and vapor-out processes of biomimetic bilayer PML-PC NFM. h IR thermal images revealing the surface temperature distribution of PAN/MIL@LiCI NFM and bilayer PML-PC NFM under one-sun illumination after a fixed time. i Surface temperature evolution of PAN/MIL@LiCI NFM and bilayer PML-PC NFM versus time under simulated sunlight irradiation of $1 \mathrm{~kW} \mathrm{~m}^{-2}$. $\mathbf{j}$ Mass change in the PAN/MIL@LiCl NFM and bilayer PML-PC NFM versus irradiation time under one-sun illumination. $\mathbf{k}$ Evolution of the water evaporation rate of PAN/MIL@LiCI NFM and bilayer PML-PC NFM as a function of time under a solar irradiation.

fast evaporation rate of bilayer PML-PC NFM under low irradiation was attributed to its superior moisture permeability, rapid moisture transport, and excellent light absorption, as well as its highly efficient light-to-heat conversion enabled by heat localization.

Dehumidification performance of a moisture pump and application models. To evaluate its practical applications, the prepared bilayer PML-PC NFM composed of a light green desiccant layer (PAN/MIL@LiCl NFM) and a black photothermal layer (PAN/CB NFM) was used as an NFM-based moisture pump. The bilayer PML-PC NFM had excellent flexibility and foldability (Fig. 5a), making it portable and convenient for practical environmental applications. In addition, the bilayer PML-PC NFM with a certain mechanical strength could be selfsupported during application (Supplementary Fig. 3). Figure 5b shows the cross-section of bilayer PML-PC NFM consisting of PAN/MIL@LiCl NFM and PAN/CB NFM. PAN/CB NFM with a 


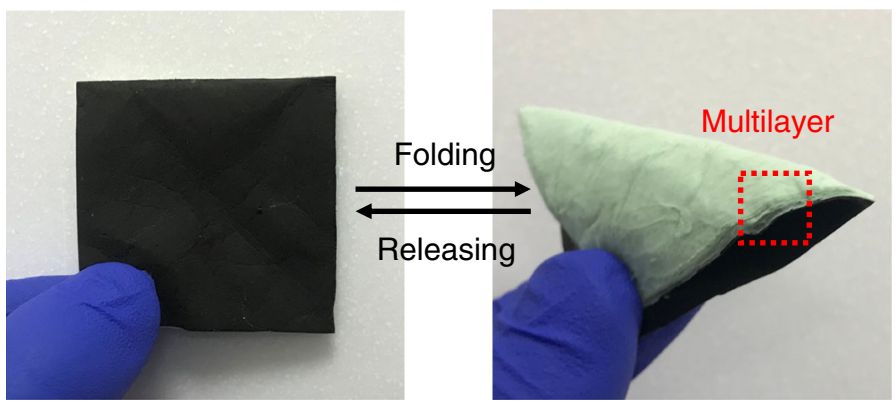

b

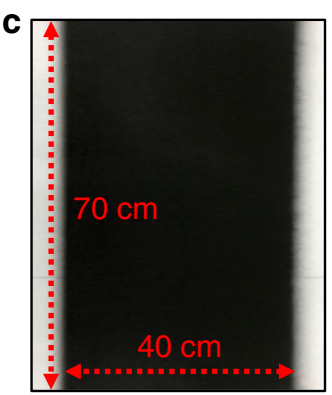

d

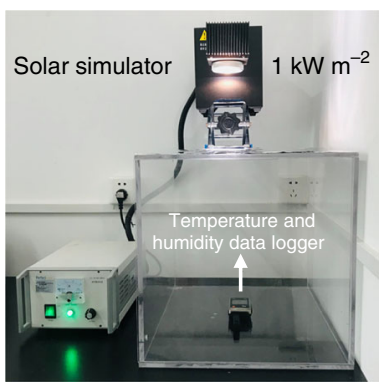

$\mathbf{e}$

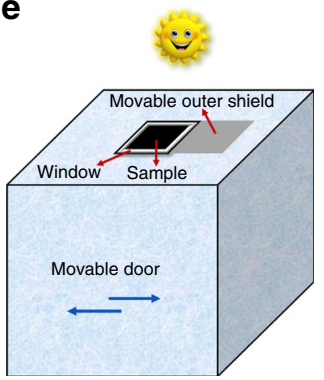

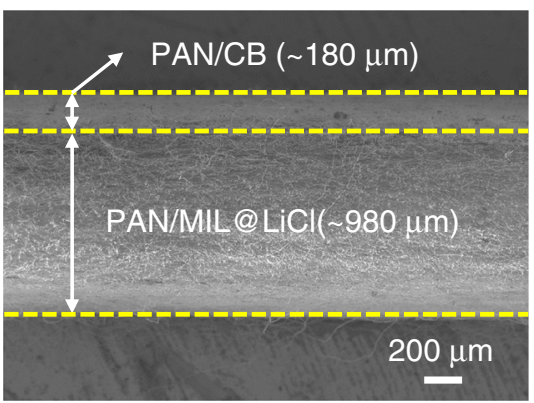

$\mathbf{f}_{\text {Direction of moisture movement }}$
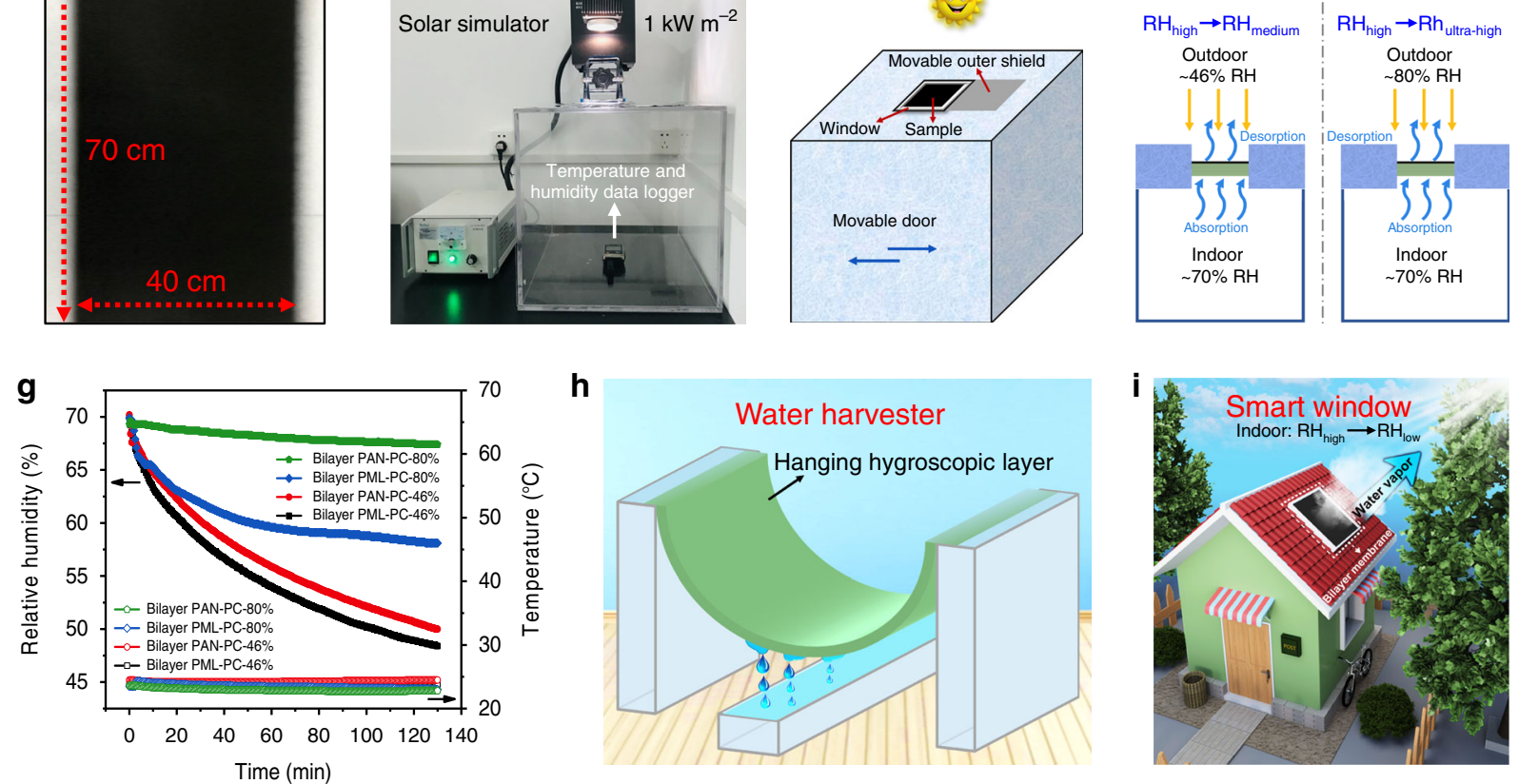

h

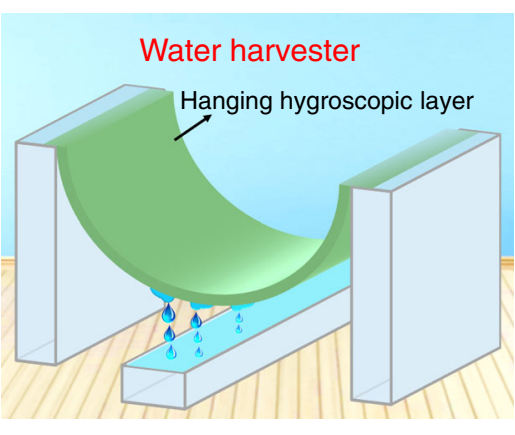

Fig. 5 Dehumidification performance and application models. a Photographs of folding test of bilayer PML-PC NFM. b Cross-sectional SEM image of bilayer PML-PC NFM consisting of PAN/MIL@LiCI NFM and PAN/CB NFM. c Scalable demonstration of bilayer PML-PC NFM. d A scaled-down model of a house for continuous dehumidification testing. e Schematic illustration of the moisture pump model under simulated sunlight irradiation. When the light from the solar simulator illuminates the surface of bilayer PML-PC NFM, the moisture in the indoor air is pumped by bilayer PML-PC NFM and then evaporates in the form of water vapor. The blue arrows represent the direction of door movement. $\mathbf{f}$ Schematics displaying moisture movement through the moisture pump model to achieve indoor dehumidification. $\mathbf{g}$ Indoor relative humidity and temperature over time under one-sun illumination for bilayer PAN-PC and PML-PC NFMs when the device was placed in environments with ambient humidities of $46 \%$ and $80 \%$, respectively. Plots showing the reduction in RH in a confined space as the bilayer NFMs absorb moisture from the humid air and evaporate outside. Application models of (h) an atmospheric water harvester by a novel hanging hygroscopic layer and (i) a smart window concept in which the bilayer membrane is used as an indoor dehumidification material.

thickness of $\sim 180 \mu \mathrm{m}$ was covered on the fluffy multilayer PAN/ MIL@LiCl NFM with a thickness of $\sim 980 \mu \mathrm{m}$. It was worth mentioning that large area $(70 \mathrm{~cm} \times 40 \mathrm{~cm})$ of bilayer PML-PC NFM could be readily fabricated using electrospinning (Fig. 5c), which is very important for practical applications.

A moisture pump prototype was constructed using the bilayer PML-PC NFM to evaluate its continuous dehumidification performance. The testing device consisted of a house model, a solar simulator, as well as a temperature and humidity data logger (Fig. 5d). The scaled-down model of a house was constructed with dimensions of $40 \mathrm{~cm} \times 50 \mathrm{~cm} \times 40 \mathrm{~cm}$, and a window with an area of $6 \mathrm{~cm} \times 6 \mathrm{~cm}$ was designed for bilayer membrane installation. Figure 5e depicts a schematic of the moisture pump model under simulated sunlight irradiation. When light from the solar simulator illuminated the surface of the bilayer PML-PC NFM, the moisture in the indoor air was pumped by bilayer PML-PC NFM and simultaneously transported outdoors in the form of water vapor. Figure $5 \mathrm{f}$ shows that the moisture actively moved from a high-humidity to a medium-humidity environment and also from a high-humidity to an ultra-high humidity environment through bilayer PML-PC NFM under sunlight irradiation. This is a unique advantage in terms of the dehumidification ability of the novel NFM-based moisture pump compared with traditional desiccants.

As a proof of concept, the $\mathrm{RH}$ reduction in a confined space was evaluated, in which the bilayer NFMs absorbed moisture from humid air and evaporated it outside (Fig. 5g). When the device was placed in an environment with an ambient humidity of $46 \%$, the indoor RH was reduced from 70 to $48.9 \%$ within $2 \mathrm{~h}$ using bilayer PML-PC NFM, while it decreased to $50.7 \%$ when using bilayer PAN-PC NFM. This dehumidification process could be influenced by air convection. Therefore, to use the moisture pump for continuous dehumidification, the device was placed in an environment with an ambient humidity of $80 \%$. The indoor 
$\mathrm{RH}$ in the house model steadily decreased from 70 to $58.3 \%$ within $2 \mathrm{~h}$ using bilayer PML-PC NFM, while it was only reduced to $67.5 \%$ using bilayer PAN-PC NFM. It was worth noting that the indoor temperature remained nearly constant, and only minimal temperature variations were caused by adsorption heat. These data confirmed that the dehumidification performance of the bilayer PML-PC NFM was significantly higher than that of the bilayer PAN-PC NFM, indicating that the synergistic effect of the MOF and LiCl played a vital role in the NFM-based moisture pump. Moreover, the final indoor humidity after dehumidification using the NFM-based moisture pump met the human body's demand for comfortable environmental humidity $(40-60 \% \mathrm{RH})$. Finally, the high-efficiency and continuous indoor dehumidification under one-sun illumination using bilayer PML-PC NFM was achieved, regardless of the external ambient humidity.

Based on the above-mentioned excellent properties of the asprepared NFM, we look forward to the broad applications of such hygroscopic NFM and propose two application models. One of the applications is an atmospheric water harvester in which PAN/ MIL@LiCl NFM is suspended in humid air for atmospheric water harvesting (Fig. 5h). Both sides of the NFM would be in contact with the humid air, which increases the capacity and rate of moisture absorption and water collection. The gaseous moisture in humid air can be successfully converted to liquid water, and water oozing from the surface of the hygroscopic NFM can drip from the bottom of the arc-shaped NFM into a water tank by gravity. The other model is a smart window concept (Fig. 5i) in which bilayer PML-PC NFM, which is capable of high-efficiency and continuous dehumidification under sunlight illumination, can potentially be used as a window screening membrane of a moisture-permeable window. Thus, it is expected to reduce the indoor humidity of living spaces suitable for human comfort.

\section{Discussion}

In this study, the wood-inspired NFM-based moisture pump (biomimetic bilayer NFM) was designed using three criteria: (1) the bilayer NFM was composed of a desiccant layer (PAN/ MIL@LiCl NFM) with a wood-like cellular network structure and a photothermal layer (PAN/CB NFM); (2) the desiccant layer must possess super hygroscopicity, fast moisture absorption and transport rates, as well as superior recyclability, and can even perform atmospheric water harvesting; (3) the bilayer NFM must be able to achieve high-efficiency and continuous indoor dehumidification while being directly powered by one-sun illumination. The first requirement is satisfied by directly electrospinning PAN/CB nanofibers onto a multilayer wood-like cellular network substrate of PAN/MIL@LiCl nanofibers. To satisfy the other two criteria, the moisture pump was designed to mimic plant transpiration. The synergistic effect of MIL-101(Cr) and $\mathrm{LiCl}$ in the desiccant layer imparted super hygroscopicity, and the nanofibrous structure significantly increased the moisture absorption-desorption rates. The $\mathrm{LiCl}$ coating and the fluffy multilayered architecture of the desiccant layer were beneficial to water harvesting, while the photothermal layer performed solar thermal conversion to generate heat for water vapor evaporation under sunlight illumination. The wood-like cellular networks and interconnected open channels of the biomimetic bilayer NFM are conducive to water transport and evaporation.

In summary, we have reported a wood-inspired NFM-based moisture pump using a facile and scalable two-step electrospinning and impregnation method for high-efficiency and continuous indoor dehumidification under sunlight illumination. The fluffy PAN/MIL@LiCl NFM with a multilayer wood-like cellular network structure possessed super hygroscopicity, a fast moisture absorption rate, as well as superior cyclability.
Hydrophilic PAN/CB NFM with highly open 3D networks displayed a high broadband solar absorption of $93 \%$ and good moisture permeability and achieved efficient solar thermal conversion, which enhanced its water evaporation. As a result, the super hygroscopic desiccant layer exhibited, to the best of our knowledge, an unprecedented moisture absorption capacity of $3.01 \mathrm{~g} \mathrm{~g}^{-1}$ at $25^{\circ} \mathrm{C}$ and $90 \% \mathrm{RH}$, achieving atmospheric water harvesting. The ability of the material to transform water from the gas phase to the liquid phase will open up a variety of possibilities for developing flexible desiccants for energy exchange systems with low energy consumption. The NFMbased moisture pump efficiently reduced the indoor $\mathrm{RH}$ to a moderate level under one-sun illumination to meet the human body's comfort demands. To the best of our knowledge, this is the first report of a flexible electrospun NFM-based moisture pump. We envision that such a super hygroscopic NFM will provide new opportunities for developing atmospheric water harvesting, moisture-permeable windows on buildings, and humidity control inside electronic devices.

\section{Methods}

General. The experimental materials and detailed synthesis procedure of MIL-101 (Cr) nanoparticles are given in the Supplementary methods.

Preparation of wood-like PAN/MIL NFM. PAN/MIL NFM was fabricated by electrospinning technique. Briefly, $22 \mathrm{wt} \%$ of MIL-101(Cr) nanoparticles were added into DMF and then dispersed under ultrasonic treatment for $2 \mathrm{~h}$. Subsequently, $8 \mathrm{wt} \%$ of PAN was added to the above solution with magnetic stirring. The blended solution was vigorously stirred for $12 \mathrm{~h}$. PAN/MIL NFM was prepared through a DXES-3 electrospinning machine (Shanghai Oriental Flying Nanotechnology Co., Ltd, China). The PAN/MIL solution was loaded into plastic syringes, and the tip-roller distance of $15 \mathrm{~cm}$ was maintained. The feed rate of $1 \mathrm{~mL} \mathrm{~h}^{-1}$ and a stable voltage of $16 \mathrm{kV}$ were applied, and the spinning process lasted $3 \mathrm{~h}$. The ambient temperature and $\mathrm{RH}$ were kept at $23 \pm 1{ }^{\circ} \mathrm{C}$ and $46 \pm 3 \%$, respectively. Finally, the as-prepared light green PAN/MIL NFM with a multilayer wood-like network structure was dried at $100{ }^{\circ} \mathrm{C}$ under vacuum.

Preparation of PAN/MIL@LiCI NFM. The impregnation method was applied to coat $\mathrm{LiCl}$ into PAN/MIL NFM. The $\mathrm{LiCl}$ solution (concentration of $5 \mathrm{wt} \%$ ) was prepared by adding $\mathrm{LiCl}$ particles to ethanol and stirring for $30 \mathrm{~min}$. Subsequently, PAN/MIL NFM was impregnated in the $\mathrm{LiCl}$ solution for $30 \mathrm{~min}$ and then dried at $100^{\circ} \mathrm{C}$. The calculation of the $\mathrm{LiCl}$ coating ratio was detailed in Supporting information.

Preparation of PAN/CB NFM. PAN/CB NFM was prepared by electrospinning technique. Briefly, $6 \mathrm{wt} \%$ of $\mathrm{CB}$ nanoparticles were added into DMF and then ultrasonic dispersed for $1 \mathrm{~h}$. Subsequently, $10 \mathrm{wt} \%$ of PAN was added into the above solution. The blended solution was vigorously stirred for $12 \mathrm{~h}$. Afterward, the electrospinning machine was applied, and the PAN/CB solution was transferred to five plastic syringes, and the tip-roller distance of $15 \mathrm{~cm}$ was maintained. The feed rate of $1 \mathrm{~mL} \mathrm{~h}^{-1}$ and a stable voltage of $20 \mathrm{kV}$ were applied, and the spinning process lasted $6 \mathrm{~h}$. The as-prepared PAN/CB NFM was deposited on a glossy paper covered roller. In addition, the ambient temperature and $\mathrm{RH}$ were $23 \pm 1{ }^{\circ} \mathrm{C}$ and $46 \pm 3 \%$, respectively. Finally, the black PAN/CB NFM was dried at $100^{\circ} \mathrm{C}$ under vacuum.

Preparation of biomimetic bilayer PML-PC NFM. Preparation of the PAN/CB solution and regulation of spinning parameters of PAN/CB NFM as described above. Differently, biomimetic PAN/MIL@LiCl NFM was covered on the earthed metallic roller for the electrospinning of PAN/CB. After $6 \mathrm{~h}$, the obtained bilayer NFM was dried at $100^{\circ} \mathrm{C}$ for $2 \mathrm{~h}$ under vacuum. Finally, the prepared bilayer PAN/ MIL@LiCl-PAN/CB NFM was denoted as bilayer PML-PC NFM.

Characterization. The microstructures of the NFMs were characterized by SEM (VEGA 3), FE-SEM (S-4800), and TEM (JEM-2100). Optical images of the NFMs and the moisture absorption, water oozing processes were recorded by a digital video camera (Canon Powershot A1100IS). $\mathrm{N}_{2}$ adsorption-desorption isotherms were evaluated by physisorption analyzer (ASAP 2460), and the specific surface area and PSD were calculated using BET model, HK model, and DFT method, respectively. XRD patterns were determined by a D/Max-2550/PC (Rigaku Co. Japan) at $\mathrm{Cu} \mathrm{Ka}$ radiation $(\lambda=1.5418 \AA$ ). The Raman spectra were recorded using a Raman spectrometer (inVia-Reflex) with an excitation laser of $532 \mathrm{~nm}$. The reflectance and transmittance spectra were measured in the range of 250-2500 nm using a UV/Vis spectrophotometer (UV3600) equipped with integrating sphere. 
The thermal images and surface temperature distribution of the NFMs were recorded through an IR thermal camera (TiS75, Fluke, American). The WVT tests were investigated by the ASTM E96 positive cup standard using a WVT tester (YG $601 \mathrm{H}$ ), and the measurements were carried out under $38^{\circ} \mathrm{C}$ and $50 \% \mathrm{RH}$. Temperature and $\mathrm{RH}$ were recorded using a temperature and humidity data logger (Testo $175 \mathrm{H1}$ ). The tensile mechanical properties of the bilayer PML-PC NFM were characterized utilizing a tensile tester (XQ-1C). All samples were dried under vacuum at $100^{\circ} \mathrm{C}$ for $3 \mathrm{~h}$ before testing.

Moisture absorption measurement. The moisture absorption capacity, cycle stability, and water oozing performance were conducted using a constant temperature and humidity chamber. The WVT tester (YG 601H) was also used as a constant temperature and humidity chamber. The moisture absorption tests were performed at $25^{\circ} \mathrm{C}$ and various humidities $(60,70,80$, and $90 \% \mathrm{RH})$. Before testing, the samples cut into circles with a radius of $3.4 \mathrm{~cm}$ were dried in an oven at $100^{\circ} \mathrm{C}$ until their weight maintained unchanged, then placed in a constant temperature and humidity chamber. The samples should be taken out at a regular interval and weighed quickly in an electronic balance with an accuracy of $0.0001 \mathrm{~g}$. During the absorption-desorption cyclic tests, the samples were maintained $6 \mathrm{~h}$ at $25^{\circ} \mathrm{C}$ and $70 \% \mathrm{RH}$ for moisture absorption and then kept $1 \mathrm{~h}$ at $100^{\circ} \mathrm{C}$ for desorbing water vapor in every cycle. Water oozing after hygroscopic saturation was observed at $90 \% \mathrm{RH}$. The moisture absorption capacity of the sample is calculated by the following formula:

$$
C_{a b s}=\Delta m / m_{0},
$$

where, $C_{a b s}$ is the moisture absorption capacity based on unit weight of raw NFM $\left(\mathrm{g} \mathrm{g}^{-1}\right), \Delta m$ is the moisture absorption quantity $(\mathrm{g})$, and $m_{0}$ is the weight of dried raw NFM (g).

Solar evaporation experiment. The solar evaporation experiment was conducted in a room with constant temperature $\left(\sim 23^{\circ} \mathrm{C}\right)$ and $\mathrm{RH}(\sim 46 \%)$. Water vapor desorption testing was performed by a standard solar simulator (PLS-SXE300). The intensity of solar irradiation was controlled at $1 \mathrm{~kW} \mathrm{~m}^{-2}$. Prior to the solar evaporation measurement, the sample reached absorption saturation at $25^{\circ} \mathrm{C}$ and $70 \%$ RH. The mass change of the sample over time under one-sun illumination was recorded every $5 \mathrm{~min}$, which was used for calculating the water evaporation rates $\left(\mathrm{kg} \mathrm{m}^{-2} \mathrm{~h}^{-1}\right)$. Each sample was tested three times.

\section{Data availability}

The authors declare that all data supporting the findings of this study are available within the article and its Supplementary information or from the corresponding author upon reasonable request. Source data are provided with this paper.

Received: 6 January 2020; Accepted: 12 June 2020;

Published online: 03 July 2020

\section{References}

1. Allouhi, A. et al. Solar driven cooling systems: an updated review. Renew. Sustain. Energy Rev. 44, 159-181 (2015).

2. Yang, L., Yan, H. \& Lam, J. C. Thermal comfort and building energy consumption implications-a review. Appl. Energy 115, 164-173 (2014).

3. AbdulHalim, R. G. et al. A fine-tuned metal-organic framework for autonomous indoor moisture control. J. Am. Chem. Soc. 139, 10715-10722 (2017).

4. Wolkoff, P. Indoor air humidity, air quality, and health-an overview. Int. J. Hyg. Environ. Health 221, 376-390 (2018).

5. Arundel, A. V., Sterling, E. M., Biggin, J. H. \& Sterling, T. D. Indirect health effects of relative humidity in indoor environments. Environ. Health Perspect. 65, 351-361 (1986).

6. Wahlgren, R. V. Atmospheric water vapour processor designs for potable water production: a review. Wat. Res. 35, 1-22 (2001).

7. Kalmutzki, M. J., Diercks, C. S. \& Yaghi, O. M. Metal-organic frameworks for water harvesting from air. Adv. Mater. 30, 1704304 (2018).

8. Kim, H. et al. Water harvesting from air with metal-organic frameworks powered by natural sunlight. Science 356, 430-434 (2017).

9. Zhao, F. et al. Super moisture-absorbent gels for all-weather atmospheric water harvesting. Adv. Mater. 31, e1806446 (2019).

10. Jani, D. B., Mishra, M. \& Sahoo, P. K. Solid desiccant air conditioning-a state of the art review. Renew. Sustain. Energy Rev. 60, 1451-1469 (2016).

11. Rotzetter, A. C. et al. Thermoresponsive polymer induced sweating surfaces as an efficient way to passively cool buildings. Adv. Mater. 24, 5352-5356 (2012).

12. Marszal, A. J. et al. Zero energy building-a review of definitions and calculation methodologies. Energy Build. 43, 971-979 (2011).
13. Deng, S., Wang, R. Z. \& Dai, Y. J. How to evaluate performance of net zero energy building-a literature research. Energy 71, 1-16 (2014).

14. Zhang, L. Z., Jiang, Y. \& Zhang, Y. P. Membrane-based humidity pump: performance and limitations. J. Membr. Sci. 171, 207-216 (2000).

15. Gao, T. et al. Architecting a floatable, durable, and scalable steam generator: hydrophobic/hydrophilic bifunctional structure for solar evaporation enhancement. Small Methods 3, 1800176 (2018).

16. Chen, C. et al. Highly flexible and efficient solar steam generation device. $A d v$. Mater. 29, 1701756 (2017).

17. Liu, Z. et al. Continuously producing watersteam and concentrated brine from seawater by hanging photothermal fabrics under sunlight. Adv. Funct. Mater. 29, 1905485 (2019).

18. Zhang, Y. Z. et al. Tuning water sorption in highly stable $\mathrm{Zr}$ (IV)-metalorganic frameworks through local functionalization of metal clusters. ACS Appl. Mater. Interfaces 10, 27868-27874 (2018).

19. Li, B. et al. Emerging multifunctional metal-organic framework materials. Adv. Mater. 28, 8819 (2016).

20. Zhu, X. W., Zhou, X. P. \& Li, D. Exceptionally water stable heterometallic gyroidal MOFs: tuning the porosity and hydrophobicity by doping metal ions Chem. Commun. 52, 6513-6516 (2016).

21. Jeremias, F., Khutia, A., Henninger, S. K. \& Janiak, C. MIL-100(Al, Fe) as water adsorbents for heat transformation purposes-a promising application. J. Mater. Chem. 22, 10148-10151 (2012).

22. Canivet, J., Fateeva, A., Guo, Y., Coasne, B. \& Farrusseng, D. Water adsorption in MOFs: fundamentals and applications. Chem. Soc. Rev. 43, 5594-5617 (2014).

23. Yan, J. et al. Adsorption isotherms and kinetics of water vapor on novel adsorbents MIL-101(Cr)@GO with super-high capacity. Appl. Therm. Eng. 84, 118-125 (2015).

24. Cao, B., Tu, Y. \& Wang, R. A moisture-penetrating humidity pump directly powered by one-sun illumination. iScience 15, 502-513 (2019).

25. Zhao, B., Peng, N., Liang, C., Yong, W. \& Chung, T. Hollow fiber membrane dehumidification device for air conditioning system. Membranes 5, 722-738 (2015).

26. Zhang, Y., Guan, J., Wang, X., Yu, J. \& Ding, B. Balsam-pear-skin-like porous polyacrylonitrile nanofibrous membranes grafted with polyethyleneimine for postcombustion $\mathrm{CO}_{2}$ capture. ACS Appl. Mater. Interfaces 9, 41087-41098 (2017).

27. Zhang, Y., Zhang, Y., Wang, X., Yu, J. \& Ding, B. Ultrahigh metal-organic framework loading and flexible nanofibrous membranes for efficient $\mathrm{CO}_{2}$ capture with long-term, ultrastable recyclability. ACS Appl. Mater. Interfaces 10, 34802-34810 (2018).

28. Dai, L. et al. Sorption and regeneration performance of novel solid desiccant based on PVA-LiCl electrospun nanofibrous membrane. Polym. Test. 64, 242-249 (2017).

29. Jiang, F., Dai, L. \& Yao, Y. Polyamide 6-LiCl nanofibrous membrane as lowtemperature regenerative desiccant with improved stability. Nanotechnology 29, 185702 (2018)

30. Zheng, X., Ge, T. S., Wang, R. Z. \& Hu, L. M. Performance study of composite silica gels with different pore sizes and different impregnating hygroscopic salts. Chem. Eng. Sci. 120, 1-9 (2014).

31. Nakabayashi, S., Nagano, K., Nakamura, M., Togawa, J. \& Kurokawa, A. Improvement of water vapor adsorption ability of natural mesoporous material by impregnating with chloride salts for development of a new desiccant filter. Adsorption 17, 675-686 (2011).

32. Tu, J. et al. Humidity sensitive property of Li-doped $3 \mathrm{D}$ periodic mesoporous silica SBA-16. Sens. Actuators B: Chem. 136, 392-398 (2009).

33. Zhu, H. et al. Wood-derived materials for green electronics, biological devices, and energy applications. Chem. Rev. 116, 9305-9374 (2016).

34. Zhu, M. et al. Tree-inspired design for high-efficiency water extraction. $A d v$. Mater. 29, 1704107 (2017).

35. Mi, X. et al. Fabrication of highly porous starch monoliths and their application as green desiccants. Polym. Adv. Technol. 23, 38-47 (2012).

36. Ge, J., Jin, Q., Zong, D., Yu, J. \& Ding, B. Biomimetic multilayer nanofibrous membranes with elaborated superwettability for effective purification of emulsified oily wastewater. ACS Appl. Mater. Interfaces 10, 16183-16192 (2018)

37. Yan, G. et al. Self-assembly of electrospun polymer nanofibers: a general phenomenon generating honeycomb-patterned nanofibrous structures. Langmuir 27, 4285-4289 (2011).

38. Zhang, S. et al. Direct electronetting of high-performance membranes based on self-assembled 2D nanoarchitectured networks. Nat. Commun. 10, 1458 (2019).

39. Tsuru, T. et al. Permeation properties of hydrogen and water vapor through porous silica membranes at high temperatures. AIChE J. 57, 618-629 (2011).

40. Albayrak, C., Barim, G. \& Dag, O. Effect of hygroscopicity of the metal salt on the formation and air stability of lyotropic liquid crystalline mesophases in hydrated salt-surfactant systems. J. Colloid Interface Sci. 433, 26-33 (2014).

41. Matsumoto, K., Sakikawa, N. \& Miyata, T. Thermo-responsive gels that absorb moisture and ooze water. Nat. Commun. 9, 2315 (2018). 
42. Nandakumar, D. K. et al. A super hygroscopic hydrogel for harnessing ambient humidity for energy conservation and harvesting. Energy Environ. Sci. 11, 2179-2187 (2018).

43. Garzón-Tovar, L., Pérez-Carvajal, J., Imaz, I. \& Maspoch, D. Composite salt in porous metal-organic frameworks for adsorption heat transformation. Adv. Funct. Mater. 27, 1606424 (2017).

44. Shah, J., Arora, M., Purohit, L. P. \& Kotnala, R. K. Significant increase in humidity sensing characteristics of praseodymium doped magnesium ferrite. Sens. Actuators A: Phys. 167, 332-337 (2011)

45. Kotnala, R. K. et al. Influence of annealing on humidity response of RF sputtered nanocrystalline $\mathrm{MgFe}_{2} \mathrm{O}_{4}$ thin films. Thin Solid Films 519, 6135-6139 (2011).

46. Lu, Y. et al. Microwave-hydrothermal synthesis and humidity sensing behavior of $\mathrm{ZrO}_{2}$ nanorods. RSC Adv. 3, 11707-11714 (2013).

47. $\mathrm{Su}, \mathrm{F}$. et al. Nitrogen-containing microporous carbon nanospheres with improved capacitive properties. Energy Environ. Sci. 4, 717-724 (2011).

48. Sun, T. et al. Rapid electron transfer by the carbon matrix in natural pyrogenic carbon. Nat. Commun. 8, 14873 (2017).

\section{Acknowledgements}

This work is supported by the National Key R\&D Program of China (No. 2016YFB0303200), the National Natural Science Foundation of China (Nos. 51925302 and 51503028), the Program for Professor of Special Appointment at Shanghai Institutions of Higher Learning (No. TP2016019), the State Key Laboratory for Modification of Chemical Fibers and Polymer Materials, Donghua University (No. KF1824), and the Fundamental Research Funds for the Central Universities and Graduate Student Innovation Fund of Donghua University (No. CUSF-DH-D-2018035).

\section{Author contributions}

Y.Z., X.W., and B.D. designed the research and wrote the paper. Y.Z. and L.W. performed the experiments. Y.Z. and J.Y analyzed the experimental results. X.W. and B.D. edited and revised the paper.

\section{Competing interests}

The authors declare no competing interests.

\section{Additional information}

Supplementary information is available for this paper at https://doi.org/10.1038/s41467020-17118-3.

Correspondence and requests for materials should be addressed to X.W. or B.D.

Peer review information Nature Communications thanks Hakyong Kim, Filippo Pierini, and other, anonymous, reviewers for their contributions to the peer review of this work. Peer review reports are available.

Reprints and permission information is available at http://www.nature.com/reprints

Publisher's note Springer Nature remains neutral with regard to jurisdictional claims in published maps and institutional affiliations.

cc (i) Open Access This article is licensed under a Creative Commons Attribution 4.0 International License, which permits use, sharing, adaptation, distribution and reproduction in any medium or format, as long as you give appropriate credit to the original author(s) and the source, provide a link to the Creative Commons license, and indicate if changes were made. The images or other third party material in this article are included in the article's Creative Commons license, unless indicated otherwise in a credit line to the material. If material is not included in the article's Creative Commons license and your intended use is not permitted by statutory regulation or exceeds the permitted use, you will need to obtain permission directly from the copyright holder. To view a copy of this license, visit http://creativecommons.org/ licenses/by/4.0/.

(C) The Author(s) 2020 